\title{
Observing the May 2015 Record Rainfall at Norman, Oklahoma, Using Various Methods
}

\author{
Claude E. Duchon \\ School of Meteorology, University of Oklahoma, Norman, Oklahoma \\ CHRISTOPHER A. Fiebrich AND BRAdLEy G. Illston \\ Oklahoma Climatological Survey, Norman, Oklahoma
}

(Manuscript received 18 July 2017, in final form 15 October 2017)

\begin{abstract}
The May 2015 record rainfall that occurred across Oklahoma was the result of a large number of highintensity rain events. A unique set of observations from gauges in the Oklahoma Mesonet, the NWS Cooperative Observer (COOP) network, the Community Collaborative Rain, Hail and Snow (CoCoRaHS) network, an experimental pit gauge system, and NWS radar was available that covered an area in and around Norman, Oklahoma. This paper documents the performance of the various gauges throughout the course of the month. Key findings are 1) observations from all methods significantly exceeded the 200-yr return interval; 2) a weighing-bucket gauge at ground level recorded amounts up to $4.5 \%$ higher than a similarly located ground-level tipping-bucket gauge and up to $8.2 \%$ higher than a nearby aboveground tipping-bucket gauge; 3 ) a manual COOP gauge recorded nearly identical (within 1.2\%) observations as compared to an automated tipping-bucket gauge at a collocated Mesonet station; and 4) observations from 26 CoCoRaHS gauges yielded an average rainfall within $1 \%$ of the aerially averaged radar rainfall derived from the Multisensor Precipitation Estimator.
\end{abstract}

\section{Introduction}

During May 2015, record-breaking rainfall was observed across Oklahoma. A new statewide monthly record of $366.8 \mathrm{~mm}$ (14.44 in.; NOAA 2017) was observed. The area in and around the city of Norman, the area of our study, recorded between 492 and $647 \mathrm{~mm}$ (19.3725.47 in.) from a cluster of 31 gauges that included the Oklahoma Mesonet, the National Weather Service (NWS) Cooperative Observer Program (COOP) network, the Community Collaborative Rain, Hail and Snow Network (CoCoRaHS), ${ }^{1}$ and gauges at ground level in an experimental pit. Every total for May, shown in Table 1, exceeded the 200-yr return interval of $490 \mathrm{~mm}$ in 30 days published in Perica et al. (2013). Rainfall was recorded on 21 of the 31 days of May. The numerous rainfall events, many of which were high

\footnotetext{
${ }^{1}$ http://www.cocorahs.org.
}

Corresponding author: Claude E. Duchon, cduchon@ou.edu intensity, provided a unique opportunity to compare the performance of a variety of rainfall-observing methods over a relatively short time period, one month, with no changes in instrumentation and instrument siting. A comparison with estimates from the radar-derived Multisensor Precipitation Estimator is also included in this study.

\section{Gauge measurement systems}

\section{a. CoCoRaHS}

CoCoRaHS (Reges et al. 2016) comprises over 37000 volunteer observers across the United States. Daily observations were available from 26 gauges in our study area throughout the month of May 2015. Each gauge has a diameter of $101.6 \mathrm{~mm}$ and is constructed of durable plastic (Fig. 1a). The capacity of the inner measuring cylinder is $25.4 \mathrm{~mm}$ ( 1 in.). Overflow can be measured by carefully filling the emptied inner cylinder with the rain collected in the outer cylinder. 
TABLE 1. The location of the 31 gauges employed in this study and their rainfall totals for the month of May 2015. The CoCoRaHS gauges are organized according to ascending totals.

\begin{tabular}{|c|c|c|c|c|c|c|c|}
\hline $\begin{array}{c}\text { CoCoRaHS } \\
\text { locations }\end{array}$ & $\begin{array}{l}\text { Total } \\
(\mathrm{mm})\end{array}$ & $\begin{array}{c}\text { CoCoRaHS } \\
\text { locations }\end{array}$ & $\begin{array}{l}\text { Total } \\
(\mathrm{mm})\end{array}$ & $\begin{array}{c}\text { CoCoRaHS } \\
\text { locations }\end{array}$ & $\begin{array}{l}\text { Total } \\
(\mathrm{mm})\end{array}$ & $\begin{array}{c}\text { CoCoRaHS } \\
\text { locations }\end{array}$ & $\begin{array}{l}\text { Total } \\
(\mathrm{mm})\end{array}$ \\
\hline Norman $5.1 \mathrm{NW}$ & 492 & Norman $3.4 \mathrm{SE}$ & 573 & Norman 5.9 SW & 596 & Norman 8.4 SE & 607 \\
\hline Noble $8.5 \mathrm{E}$ & 527 & Norman 2.0 WSW & 579 & Hall Park 2.4 WNW & 596 & Norman 2.7 SSW & 613 \\
\hline Moore $3.6 \mathrm{WNW}$ & 534 & Norman 1.7 SSE & 581 & Norman $3.4 \mathrm{~S}$ & 598 & Norman $9.2 \mathrm{E}$ & 637 \\
\hline Moore $0.1 \mathrm{SE}$ & 541 & Norman 5.5 ESE & 587 & Norman 2.8 SSW & 599 & Hall Park 2.0 SSE & 639 \\
\hline Norman 3.5 SSE & 544 & Noble $3.3 \mathrm{SE}$ & 590 & Norman 2.7 SW & 600 & Norman 2.6 SSW & 644 \\
\hline Moore 1.3 ENE & 557 & Norman 3.1 WNW & 593 & Norman 2.1 SE & 601 & & \\
\hline Oklahoma City $10.9 \mathrm{~S}$ & 570 & Norman 5.4 ESE & 595 & Norman 5.8 WSW & 606 & & \\
\hline Other gauge locations & Total (mm) & & & & & & \\
\hline NWCM & 594 & & & & & & \\
\hline NWC NWS COOP & 587 & & & & & & \\
\hline Norman Mesonet TBN & 594 & & & & & & \\
\hline Norman Mesonet TBP & 618 & & & & & & \\
\hline Norman Mesonet WBP & 647 & & & & & & \\
\hline
\end{tabular}

\section{b. Oklahoma Mesonet}

The Oklahoma Mesonet operates 121 environmental monitoring stations across Oklahoma (Brock et al. 1995; McPherson et al. 2007). Each site contains two MetOne ${ }^{2}$ 380 tipping-bucket rain gauges with 12-in. diameter inlets (Fig. 1b), surrounded by an Alter shield (Alter 1937). Data from both the Norman and National Weather Center (NWC) Mesonet stations were included in this study.

\section{c. Experimental pit}

The Oklahoma Mesonet also operates an experimental pit gauge system near the Norman Mesonet site that contains a MetOne 380 tipping-bucket rain gauge and a Geonor ${ }^{3}$ model T-200B vibrating wire weighing gauge (Fig. 1c) with an inlet area of $200 \mathrm{~cm}^{2}$ and a capacity of $600 \mathrm{~mm}$. The inlet of each gauge was at ground level, and a layer of light oil covered the mixture of water and antifreeze to prevent evaporation.

\section{d. $C O O P$}

The NWS COOP network (National Research Council 1998) consists of approximately 10000 volunteer observers across the nation. The COOP gauge is an 8-in. standard gauge that has an inner tube that overflows into a larger outer tube for measuring rain amounts up to 20 in. The Norman COOP gauge (Fig. 1d) included in this study is located at the National Weather Center and was read and recorded by a staff member of the NWS Norman Weather Forecast Office.

\footnotetext{
${ }^{2}$ http://metone.com.

${ }^{3} \mathrm{http} / / /$ geonor.com.
}

\section{e. Gauge locations}

The locations in the study area of the four kinds of gauges in sections $2 \mathrm{a}-2 \mathrm{~d}$ are shown in Fig. 1e.

\section{Comparison among all gauges}

The NWS COOP station is located $124 \mathrm{~m}$ south of the National Weather Center Mesonet (NWCM) station. The NWCM tipping-bucket gauge is enclosed by a $1.6 \mathrm{~m} \times 1.7 \mathrm{~m}$ Alter shield while the COOP gauge is free standing. These two independent sets of observations tracked each other remarkably well, and at the end of the month, their difference was only $1.2 \%: 586.7 \mathrm{~mm}$ for the COOP gauge and $593.9 \mathrm{~mm}$ for the NWCM gauge (Fig. 2a). This result was somewhat surprising given the uniquely different physical properties of the two gauges and their responses to wind speed and rain rate. The tipping-bucket gauge likely experienced undercatch due to both high rain rate and high wind speed, in spite of its Alter shield (Duchon and Essenberg 2001; Duchon and Biddle 2010), while the COOP gauge likely experienced undercatch due only to high wind speed. The COOP gauge funnel lip (distance between the rim of the funnel and the inlet above) is $5.9 \mathrm{~cm}$, while for the NWCM gauge it is $10.4 \mathrm{~cm}$. The taller lip of the tipping-bucket gauge is a consequence of laboratory experiments that showed significant splash-out with the original design height of $2.8 \mathrm{~cm}$ (Shafer et al. 2000). Another difference between the gauges is that the height of the inlet above ground level is $61 \mathrm{~cm}$ for the NWCM gauge and $107 \mathrm{~cm}$ for the COOP gauge. Because of the normal increase in wind speed with height above the surface, a slightly greater undercatch by the latter gauge would be expected, especially for small raindrops. However, to establish 
(a)

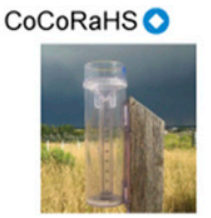

(b) MetOne $\circledast \mathbf{O}$

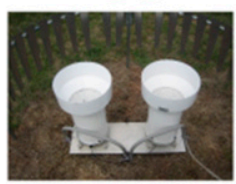

(c) Geonor $\circledast$

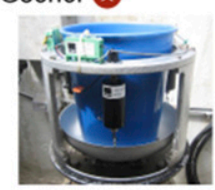

(d) $\mathrm{COOPO}$

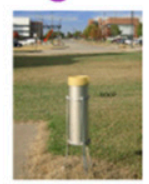

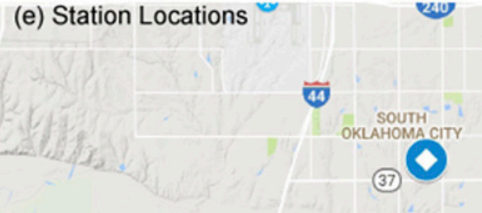

$\longdiv { 4 }$

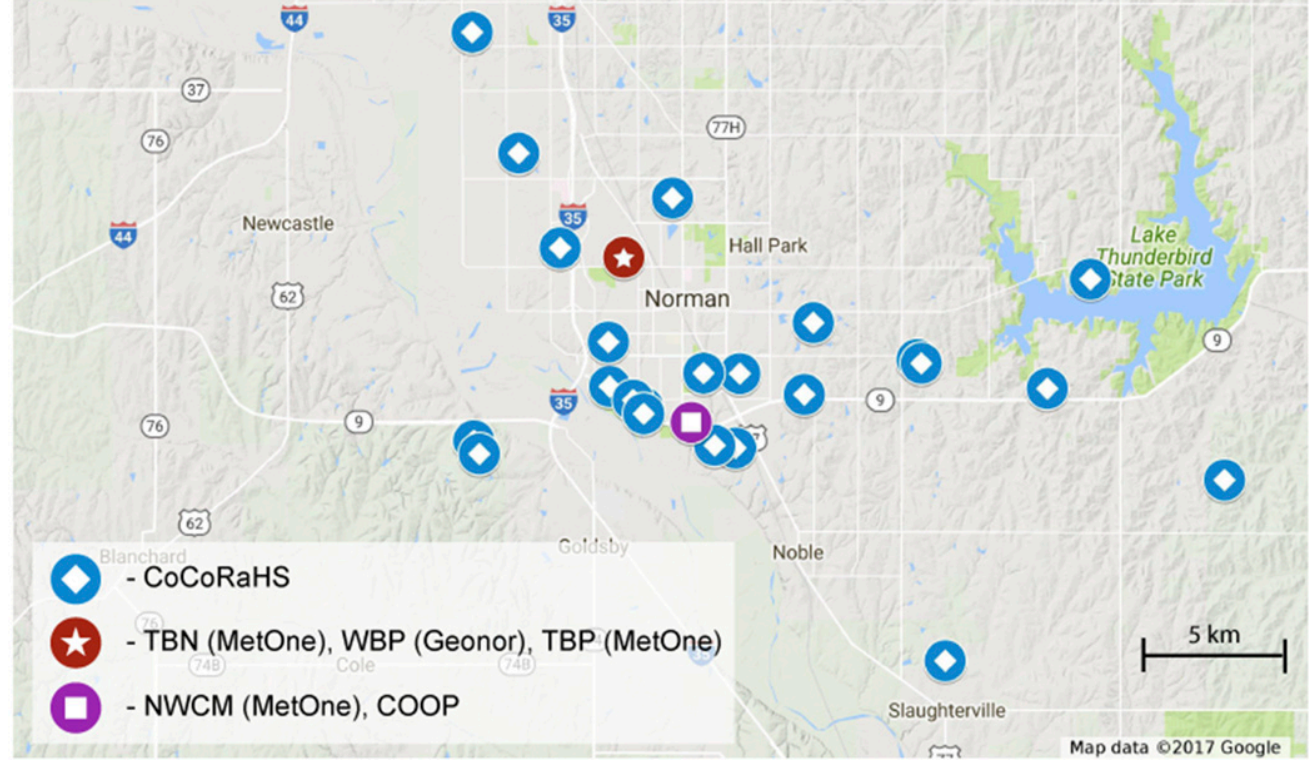

उ3

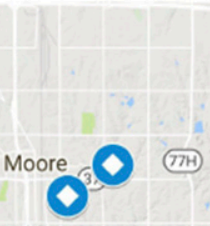

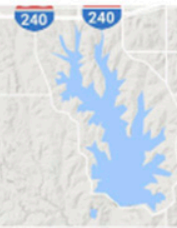

$\rightarrow$

FIG. 1. The rain gauges used in this study are shown in photographs: (a) CoCoRaHS, (b) MetOne tipping-bucket, (c) Geonor weighingbucket (with case removed), and (d) COOP. (e) The locations of these gauges.

numerical values for each source of undercatch is beyond the scope of this study. In the end, it appears that the combination of undercatch due to both wind speed and rain rate for the NWCM tipping-bucket gauge was balanced by the enhanced undercatch due to wind speed and potential splash-out for the COOP gauge.

Significant agreement was also found at many of the CoCoRaHS stations. The two closest-spaced CoCoRaHS stations, Norman 5.4 ESE and Norman 5.5 ESE (Table 1), separated by $210 \mathrm{~m}$, reported 595 and $587 \mathrm{~mm}$, respectively, a difference of $1.4 \%$. The second closest-spaced CoCoRaHS stations, Norman 2.7 SSW and Norman 2.8 SSW (Table 1), separated by $240 \mathrm{~m}$, reported 613 and $599 \mathrm{~mm}$, respectively, a difference of $2.3 \%$. Despite the low-tech nature of the CoCoRaHS gauges, these comparisons suggest that reliable rainfall amounts can be obtained from these gauges.

The most closely spaced gauges comprise the tippingbucket gauge (TBN) at the Norman Mesonet site, a tipping-bucket gauge in a pit (TBP), and a weighingbucket gauge in the same pit (WBP). The pit gauges are $95 \mathrm{~m}$ from TBN. Of the 21 rain days during the month, the daily totals among the three gauges were equal to or less than $0.254 \mathrm{~mm}(0.01 \mathrm{in}$.) on six days. The same relationship was observed between the daily totals from TBN and TBP on 10 of the 21 days. These differences suggest that the biases among the gauges are within measurement resolution of the tipping-bucket gauges.

Despite the close spacing of these gauges, the monthly totals ranged from $646.9 \mathrm{~mm}$ at WBP to $617.7 \mathrm{~mm}$ at TBP (4.5\% less than WBP) and $594.1 \mathrm{~mm}$ at TBN $(8.2 \%$ less than WBP). The cumulative daily amounts are shown in Fig. 2b. The daily data (not shown) indicated that when the rainfall exceeded $25 \mathrm{~mm}$, WBP had the highest amount, TBP the second highest, and, with one exception, TBN the least. The exception occurred on the day TBP and TBN had the same amount, $26.42 \mathrm{~mm}$. Upon closer inspection of the eight days of May 2015 that had rainfall greater than $25 \mathrm{~mm}$, it was found that all had maximum 1-min rain rates between 73 and $171 \mathrm{~mm} \mathrm{~h}^{-1}$. The maximum wind speed among the eight rain events ranged from 7.3 to $20.6 \mathrm{~m} \mathrm{~s}^{-1}$. Duchon and Biddle (2010) found that when wind speeds were greater than about $5 \mathrm{~m} \mathrm{~s}^{-1}$ and 1-min rain rates were greater than about $50 \mathrm{~mm} \mathrm{~h}^{-1}$, undercatch by tipping-bucket gauges relative to a weighing gauge at ground level were frequently observed. Thus, the results in Fig. $2 \mathrm{~b}$ are consistent with previous work.

To investigate the impact of rain rate and wind speed on undercatch by TBP and TBN, an intense rain event on 7 May lasting slightly more than an hour was 

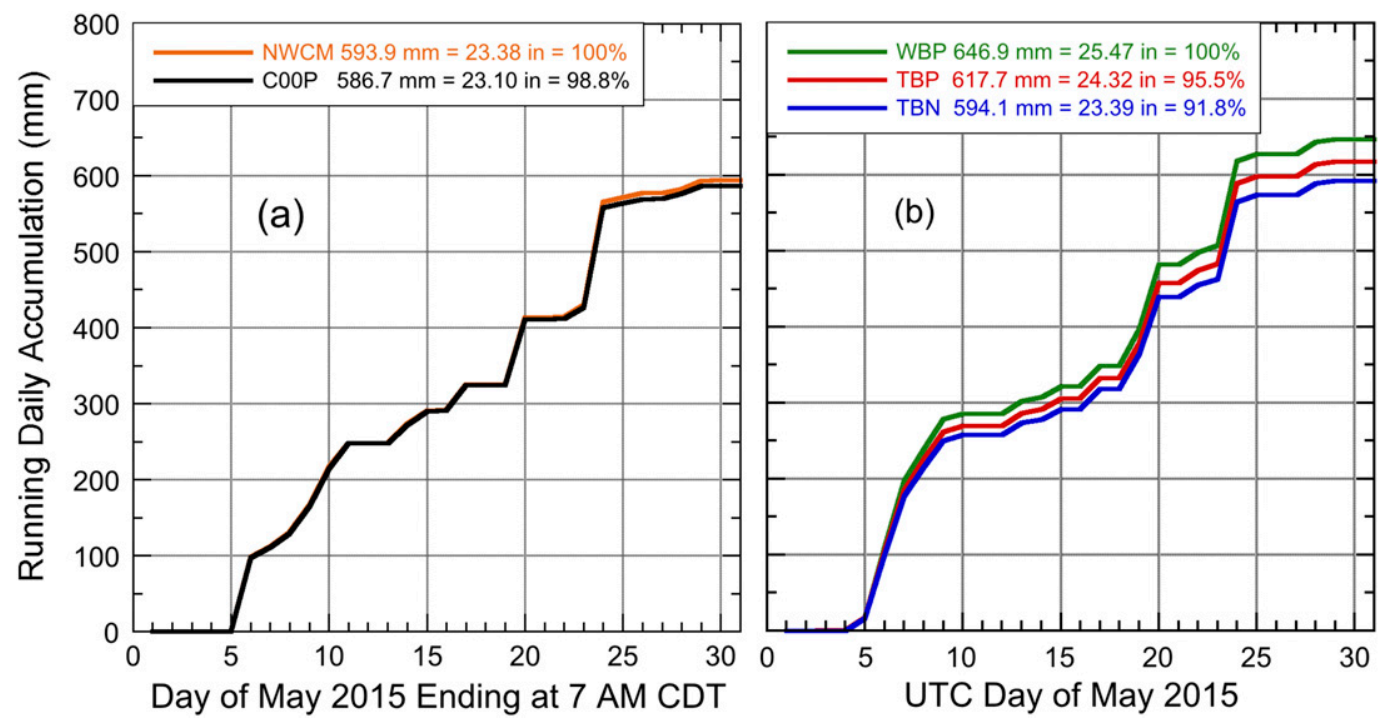

FIG. 2. Running daily accumulations for the (a) NWCM and COOP gauges and (b) WBP, TBP, and TBN gauges for May 2015.

examined. Figure 3a shows the time series of 1-min accumulations such that at the end of the event, TBP recorded $7.1 \mathrm{~mm}$ and TBN $8.6 \mathrm{~mm}$ less than WBP. The two primary sources of these differences can be found in Figs. $3 \mathrm{~b}$ and $3 \mathrm{c}$. The former shows the time series of departures of the two tipping-bucket gauges from the reference weighing-bucket gauge in addition to the rain rate from WBP. The period from minutes 120 to 130 shows that both TBP and TBN experienced substantial undercatch. Most of the time rain rates exceeded $90 \mathrm{~mm} \mathrm{~h}^{-1}$ and were as high as $170 \mathrm{~mm} \mathrm{~h}^{-1}$. It can be seen further that the rate of accumulated undercatch by TBN considerably exceeded that of TBP. During the same period, Fig. $3 \mathrm{c}$ shows that the $2-\mathrm{m}$ wind speed increased from about 3 to almost $13 \mathrm{~m} \mathrm{~s}^{-1}$, significantly affecting TBN but minimally affecting TBP. During the period from minutes 130 to 136, while the wind average wind speed is about the same as the previous $10-$ min period, the average rain rate of $32 \mathrm{~mm} \mathrm{~h}^{-1}$ $\left(0.54 \mathrm{~mm} \mathrm{~min}^{-1}\right)$ is sufficiently low that the increase in undercatch of TBP and TBN during this period is within their resolution. (Also, recall the remark in the penultimate sentence in the previous paragraph.) In response to the increased rain rate to $70 \mathrm{~mm} \mathrm{~h}^{-1}$ at minute 138 , there is a small increase in accumulated undercatch by TBP and a slightly larger increase by TBN due to wind speed. From about minute 146 to minute 159, TBN shows a decrease in undercatch of $1.1 \mathrm{~mm}$ due to, presumably, a higher rain rate at its location than at the location of the other two gauges (recall their 95-m separation), while the wind speed is less than $6 \mathrm{~m} \mathrm{~s}^{-1}$ and as low as $1 \mathrm{~m} \mathrm{~s}^{-1}$. There is another notable increase in rain rate from minute 159 to minute 165 along with a 1 -min spike in wind speed of almost $10 \mathrm{~m} \mathrm{~s}^{-1}$ while, otherwise, the average wind speed is somewhat less than $5 \mathrm{~m} \mathrm{~s}^{-1}$. The consequence is that both tipping-bucket gauges show a similar increase in accumulated undercatch. Last, there is a small increase in accumulated undercatch around minute 171 due to a rain rate of approximately $50 \mathrm{~mm} \mathrm{~h}^{-1}$.

Unfortunately, there is no simple way to correct aboveground rain rates measured by tipping-bucket gauges. Separating the effects of undercatch due to rain rate and wind speed is complicated by the impact of variable drop size that strongly influences undercatch due to wind speed (Folland 1988; Nešpor and Sevruk 1999; Theriault et al. 2012). Undercatch due to high rain rate alone can be reasonably addressed with appropriate laboratory calibration (Marsalek 1981; Humphrey et al. 1997; Duchon et al. 2014).

In conclusion, the accumulated undercatch by TBP and TBN shown in Fig. 3a can be effectively explained through the analysis of Figs. $3 b$ and $3 c$. The interplay among the three figures is typical of the other seven high rain rate-high wind speed days out of a total of the 21 rain days that occurred in May.

\section{Comparison with radar rainfall estimates}

The point measurements from in situ gauges were also compared with the Stage-IV NWS Arkansas-Red Basin River Forecast Center (ABRFC) rainfall estimates, computed on a $4 \mathrm{~km} \times 4 \mathrm{~km}$ Hydrologic Rainfall Analysis Project (HRAP) grid system. The monthly radar data are the output from a precipitation estimator, 

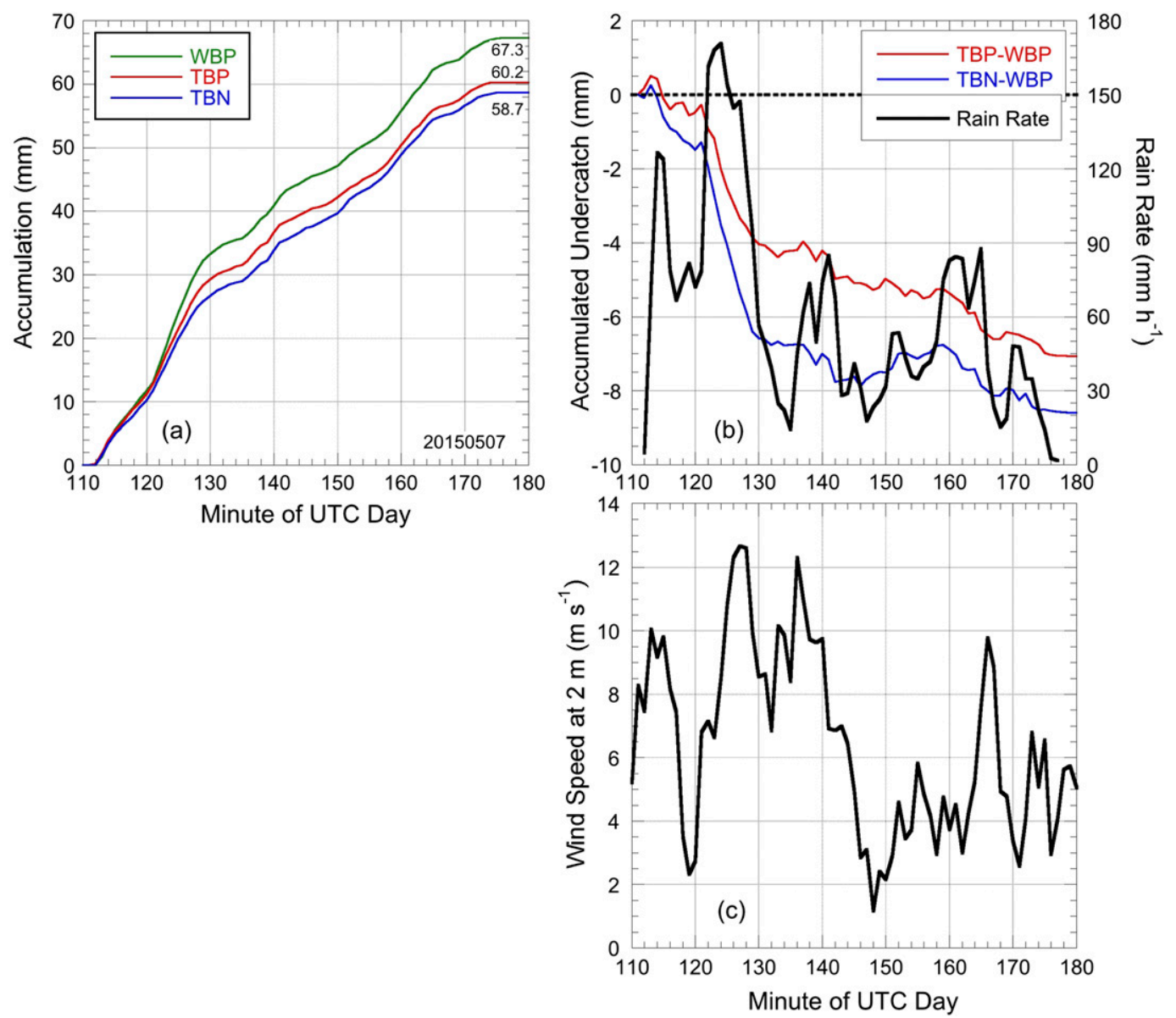

FIG. 3. (a) The 1-min accumulations from the two pit gauges and one aboveground gauge during a 70-min period with intense rainfall. Storm totals are shown in the upper right. (b) Accumulated undercatch from the tippingbucket gauges relative to the weighing-bucket gauge and 1-min rain rates. (c) Wind speed at $2 \mathrm{~m}$.

called P3, designed specifically for the ABRFC, but is generically similar to the Multisensor Precipitation Estimator ${ }^{4}$ used at other river forecast centers. Precipitation estimators employ software to adjust, and thus improve, radar estimates using hourly and daily observations from various surface rain gauges. These gauges include those in the networks listed in section 2 in addition to the U.S. Army Corps of Engineers river and reservoir gauge network. ${ }^{5}$ Because point estimates (gauges) are fundamentally different than areal estimates (radar), differences between these two kinds of measurements are expected.

Figure 4 shows the May 2015 color-coded radar pixel values in millimeters. Each color delineates a range in rainfall of $10.16 \mathrm{~mm}$; the value associated with a given color is the upper limit of this range. The location of and

\footnotetext{
${ }^{4}$ http://www.srh.noaa.gov/abrfc/?n=pcpn_methods.

${ }^{5} \mathrm{http} / / /$ www.swt-wc.usace.army.mil.
}

May rainfall from all 31 gauges in Table 1 are superimposed on the radar grid.

The comparative results are shown in Fig. 5. Clearly, there is considerable disparity between radar estimates and gauge observations. The maximum difference was $94 \mathrm{~mm}$ at pixel 2 where the gauge location is Norman 9.2 E (see Table 1). In spite of significant individual radargauge differences, the average radar-gauge difference over all pixels was only $4 \mathrm{~mm}(<1 \%)$. The adjustment process by which the radar estimates are fine-tuned with the hundreds of point estimates from gauges is a somewhat subjective process. Because of the range of point observations across this small area, it is obvious that the radar estimate cannot be adjusted by each gauge. If an adjustment was made, it was likely that only one representative gauge was used (H. Crowley 2017, personal communication). Thus, it is quite satisfying to find overall agreement between the various point measurements and the radar estimates. 


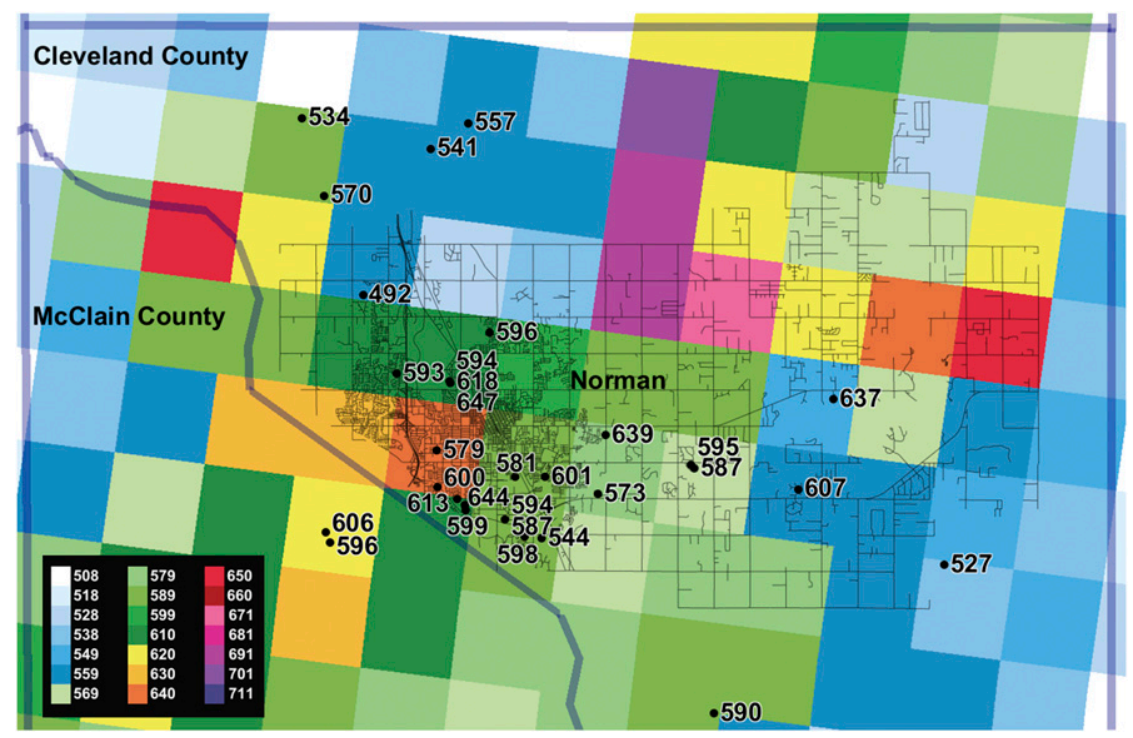

FIG. 4. ARBFC radar rainfall totals on a $4 \mathrm{~km} \times 4 \mathrm{~km}$ grid and totals from $26 \mathrm{CoCoRaHS}$ gauges, the NWS COOP gauge, three tipping-bucket gauges, and a weighing-bucket gauge (see Fig. 1, Table 1). The table in the lower left shows the color-coded radar rainfall estimates in increments of $10.16 \mathrm{~mm}(0.4 \mathrm{in}$.). County lines are in gray.

\section{Summary}

One of the areas in Oklahoma with the greatest rainfall during May 2015, in which a new statewide monthly rainfall record was established, was the area in and around Norman. Within this area, there were 31 surface gauges as well as radar that provided an opportunity to perform comparisons of various methods for observing rainfall.

The results from nearly collocated gauges at the Norman Mesonet station indicated that high wind speed and high rain rate likely caused the aboveground tipping-bucket gauge to report $8.2 \%$ lower rainfall than a ground-level weighing-bucket gauge. Because aboveground gauges are employed in all surface observations, it is highly probable that the official record of rainfall for May (NOAA 2017) is an underestimate of the actual rainfall.

The possibility of correcting observed rain rates from tipping-bucket gauges is of interest. The development of a practical correction scheme, however, is difficult due to a number of factors. In the typical case of an aboveground gauge, these factors include wind speed, rain rate, drop size distribution, and the design and physical condition of the gauge. While undercatch related to rain rate can be experimentally determined in a laboratory, as noted earlier, quantifying undercatch related to wind speed is far more challenging because it is dependent on actual gauge design and drop size distribution, which is usually unknown. Moreover, gauge calibration over long periods of field exposure can change. For these reasons, we have not attempted to develop a correction scheme for the tipping-bucket design used here.

Another finding from this study was that a Mesonetstyle tipping-bucket gauge at the National Weather

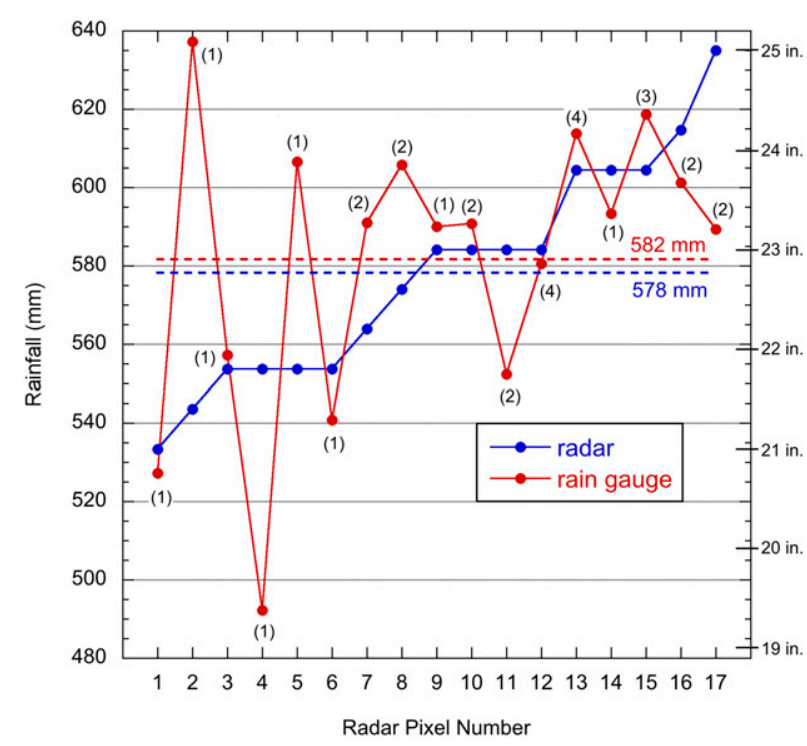

FIG. 5. Comparison of May rainfall totals for each radar pixel that has one or more gauges (given in parentheses) in its boundary shown in Fig. 4. The radar pixels are numbered from lowest to highest accumulation. If there are two or more gauges in a pixel, their average is shown. 
Center recorded daily and monthly totals very similar to those from the NWS COOP gauge located $124 \mathrm{~m}$ away. The tipping-bucket gauge was likely influenced by both wind and rain rate effects, while the COOP gauge was likely influenced by wind and splash-out effects. Without investigating the actual values of the factors contributing to undercatch, we conclude they acted in such a way to be nearly balanced for both gauges.

Last, it was found that gridded radar rainfall estimates agreed very well with gauge measurements when averaged over space and time. When averaged over all 17 pixels containing one or more gauges, the May radar rainfall differed by $4 \mathrm{~mm}$, or less than $1 \%$, from the average of all gauges.

Acknowledgments. We wish to acknowledge David Grimsley and Ryan Brashear for their careful calibration of Mesonet rain gauges and Cynthia Luttrell for overseeing data quality assurance of both Mesonet and CoCoRaHS observations. We also express our thanks to Lee Crowley of the Arkansas-Red Basin River Forecast Center for his data support and valuable comments on the text. This work was supported by the Oklahoma Mesonet, which is jointly operated by Oklahoma State University and the University of Oklahoma, and the School of Meteorology, University of Oklahoma.

\section{REFERENCES}

Alter, C. J., 1937: Shielded storage precipitation gages. Mon. Wea Rev., 65, 262-265, https://doi.org/10.1175/1520-0493(1937)65<262: SSPG $>2.0 . \mathrm{CO} ; 2$.

Brock, F. V., K. C. Crawford, R. L. Elliott, G. W. Cuperus, S. J. Stadler, H. L. Johnson, and M. D. Eilts, 1995: The Oklahoma Mesonet: A technical overview. J. Atmos. Oceanic Technol., 12, 5-19, https://doi.org/10.1175/1520-0426(1995)012<0005: TOMATO $>2.0 . \mathrm{CO} ; 2$.

Duchon, C. E., and G. R. Essenberg, 2001: Comparative rainfall observations from pit and aboveground rain gauges with and without wind shields. Water Resour. Res., 37, 3253-3263, https://doi.org/10.1029/2001WR000541.

_ , and C. J. Biddle, 2010: Undercatch of tipping-bucket gauges in high rain rate events. $A d v$. Geosci., 25, 11-15, https://doi.org/ 10.5194/adgeo-25-11-2010.
— C. Fiebrich, and D. Grimsley, 2014: Using high-speed photography to study undercatch in tipping-bucket rain gauges. J. Atmos. Oceanic Technol., 31, 1330-1336, https://doi.org/ 10.1175/JTECH-D-13-00169.1.

Folland, C. K., 1988: Numerical models of the rain gauge exposure problem, field experiments and an improved collector design. Quart. J. Roy. Meteor. Soc., 114, 1485-1516, https://doi.org/ 10.1002/qj.49711448407.

Humphrey, M. D., J. D. Istok, J. Y. Lee, J. A. Hevesi, and A. L. Flint, 1997: A new method for automated dynamic calibration of tipping-bucket rain gauges. J. Atmos. Oceanic Technol., 14, 1513-1519, https://doi.org/10.1175/1520-0426(1997)014<1513: ANMFAD $>2.0 . \mathrm{CO} ; 2$.

Marsalek, J., 1981: Calibration of the tipping-bucket rain gauge. J. Hydrol., 53, 343-354, https://doi.org/10.1016/ 0022-1694(81)90010-X.

McPherson, R. A., and Coauthors, 2007: Statewide monitoring of the mesoscale environment: A technical update on the Oklahoma Mesonet. J. Atmos. Oceanic Technol., 24, 301-321, https://doi.org/10.1175/JTECH1976.1.

National Research Council, 1998: Future of the National Weather Service Cooperative Observer Network. National Academies Press, $65 \mathrm{pp}$.

Nešpor, V., and B. Sevruk, 1999: Estimation of wind-induced error of rainfall gauge measurements using a numerical simulation. J. Atmos. Oceanic Technol., 16, 450-464, https://doi.org/ 10.1175/1520-0426(1999)016<0450:EOWIEO > 2.0.CO;2.

NOAA, 2017: The official monthly rainfall amounts for Oklahoma (state code 034). NOAA File climdiv-pcpnst-v1.0.0-20171106, ftp://ftp.ncdc.noaa.gov/pub/data/cirs/climdiv/.

Perica, S., and Coauthors, 2013: Precipitation-Frequency Atlas of the United States. NOAA Atlas 14, Vol. 8, version 2.0, 289 pp., http://www.nws.noaa.gov/oh/hdsc/PF_documents/ Atlas14_Volume8.pdf.

Reges, H. W., N. Doesken, J. Turner, N. Newman, A. Bergantino, and Z. Schwalbe, 2016: CoCoRaHS: The evolution and accomplishments of a volunteer rain gauge network. Bull. Amer. Meteor. Soc., 97, 1831-1846, https://doi.org/10.1175/ BAMS-D-14-00213.1.

Shafer, M. A., C. A. Fiebrich, D. S. Arndt, S. E. Fredrickson, and T. W. Hughes, 2000: Quality assurance procedures in the Oklahoma Mesonetwork. J. Atmos. Oceanic Technol., 17, 474-494, https://doi.org/10.1175/1520-0426(2000)017<0474: QAPITO $>2.0 . \mathrm{CO} ; 2$.

Theriault, J. M., R. Rasmussen, K. Ikeda, and S. Landolt, 2012: Dependence of snow gauge collection efficiency on snowflake characteristics. J. Appl. Meteor. Climatol., 51, 745-762, https://doi.org/10.1175/JAMC-D-11-0116.1. 